\title{
TEATRO DE BONECOS COMO DISPOSITIVO PEDAGÓGICO COM ESTUDANTES DO ENSINO MÉDIO
}

Marcelo Silva Mendes

Recebido em 02/07/2017

Aprovado em 30/10/2017 
Este artigo apresenta parte de uma pesquisa de campo desenvolvida em uma Escola Estadual de Ensino Médio, localizada na região da grande Florianópolis, Santa Catarina. A pesquisa consiste no uso do teatro de bonecos com a técnica de animação direta-visível por alunos de nível Médio regular na disciplina de Artes. O objetivo da pesquisa é experimentar a relação entre os princípios técnicos da linguagem mencionada, o processo de conscientização corporal e a importância do saber da experiência, segundo Jorge Larrosa, a partir do uso do teatro de bonecos. Embora utilize o termo "dispositivo pedagógico" de Basil Bernstein, não tenho a pretensão de aprofundar, neste momento da pesquisa, esse modelo teórico que define o que pode ser um dispositivo pedagógico. O termo é desenvolvido por Bernstein (1996) como uma condição para a produção, a reprodução e a transformação da cultura. O autor afirma que existem três tipos de regras que constituem um dispositivo pedagógico, sendo elas: regras distribuitivas, regras recontextualizadoras e regras avaliativas (BERNSTEIN, 1996). A teoria do dispositivo pedagógico foi idealizada como um "modelo de análise processual, em que um campo específico de conhecimento, uma disciplina escolar, por exemplo, pode ser transformada ou 'pedagogizado' a fim de constituir conhecimentos e conteúdos escolares, além de relações transmitidas" (MAINARDES; STREMEL, 2010). Entretanto, é possível estabelecer um paralelo entre o sentido duplo da palavra "manipulação" e a semelhança entre a exigência da existência de um processo de conscientização corporal - para realizar uma animação adequada com a importância do "dispositivo pedagógico" na descrição e análise das relações que se estabelecem no interior das salas de aula, denunciando as suas estruturas de poder e controle social. Esta estratégia de ação relaciona-se com a exploração de criação no ambiente de ensino, dentro de uma atmosfera de valorização da alteridade, de modo que seja possível o desenvolvimento de reflexões e questionamentos sobre práticas pedagógicas e processos de ensino e aprendizagem no contexto escolar. A pesquisa proposta é parte do desenvolvimento de uma pesquisa de Mestrado Profissional em Artes (PROF-ARTES).

Palavras-Chave: Escola pública; Teatro de bonecos; Alteridade.

\section{A MiLENAR ARTE BUNRAKU}

$\mathrm{N}$

as primeiras décadas do século $\mathrm{XX}$, ocorreu uma inovação no teatro de bonecos clássico, em decorrência das fortes influências do teatro japonês, com a introdução da técnica popularmente conhecida como Bunraku. Esta técnica, ainda bastante empregada nos tempos atuais, utiliza "bonecos animados através de um complexo sistema de condução, no qual o boneco pode ser animado por vários manipuladores" (BALARDIM, 2004, p. 72). Geralmente, a manipulação destes bonecos é realizada por um mestre mais experiente, responsável pela movimentação da cabeça do boneco e outras duas pessoas, na maioria das vezes, aprendizes do mestre, tornam-se responsáveis por mover seus pés e mãos. 
O termo Bunraku está associado ao artista do século XIX, Uemura Bunrakuken, responsável por transformar a pacata cidade de Osaka em um pitoresco centro de teatro de bonecos (AMARAL, 1996). O Bunraku não é considerado apenas uma técnica teatral, mas sim, um gênero teatral milenar japonês, pois este recurso técnico permite uma movimentação realista, uma vez que, a movimentação dos bonecos se assemelha aos movimentos humanos. Durante a encenação, os atores utilizam vestimentas de coloração preta, para não interferir na atenção do público com os bonecos.

A arte Bunraku ganhou destaque rapidamente na Ásia e na Europa oriental, e passou a ser mais conhecida na América do Norte, em especial nos Estados Unidos da América e no Canadá, nos anos 1960, com a realização de uma turnê de um pequeno grupo de artistas japoneses que faziam a animação de um boneco (SOUZA, 2008).

A incorporação deste recurso trouxe novas possibilidades artísticas e estéticas para o teatro de bonecos ocidental. Valores antigos foram questionados e outras formas de teatro de bonecos foram experimentadas. $\mathrm{O}$ que facilitou o modo de se pensar no teatro de animação e, especificamente na técnica direta-visível, como exemplo real de influência transformadora das tradições. Idealiza-se que a utilização desta técnica direta-visível possa ser associada a abordagens educativas, desde que haja a hibridização entre linguagens e técnicas artísticas, como algo intrínseco ao processo de um ensino interdisciplinar, procurando a integração entre teoria e prática escolar, emoção e razão, ciência e artes.

Visto as possibilidades de integração dos contextos teatral e escolar, este trabalho visa apresentar algumas possibilidades de aplicação da arte Bunraku com estudantes de uma turma de Ensino Médio em uma escola pública estadual da grande Florianópolis, através da técnica de animação de boneco de manipulação direta-visível.

Esta pesquisa pode ser considerada um importante auxílio no processo de preparação corporal dos estudantes, visto que, no sistema de ensino atual, estes passam a maior parte do tempo sentados. Além de propiciar momentos em que irão se exercitar de forma descontraída, a aplicação da arte Bunraku propiciará uma abordagem afetiva, pois, todos os participantes, tanto os atores, como quem participa, realizarão juntos uma interpretação dos fatos ocorridos durante as encenações.

O processo investigativo em teatro de bonecos deve ser pensado de modo que as atividades não se limitem apenas ao ponto de vista da confecção, mas que, na prática destas atividades, sejam aliados do desenvolvimento de capacidades criativas dos estudantes, considerando-se a potencialidade que este tipo de linguagem gera no processo de ensino e aprendizagem na escola. Capacidades estas que os estudantes precisam desenvolver para resolver os impasses que o processo de construção das animações exige. 
Isto se relaciona principalmente com o manuseio de diferentes materiais plásticos e suas respectivas ferramentas e técnicas de execução. Também está relacionado ao enfrentamento da resistência em lidar com o próprio corpo e em interagir com o corpo do outro.

Este tipo de abordagem potencializa a dinâmica dos procedimentos tanto metodológicos, quanto pedagógicos, e oferece aos participantes a efetivação da relação consigo e com o outro, mediada pelo uso do boneco e por seus processos de criação e construção. Estas reflexões permitiram vislumbrar outra perspectiva da pesquisa que considera fundamental trabalhar a partir da noção de alteridade na educação.

\section{EU, O BONECO E O OUTRO}

experiência vivida e materializada pelos estudantes no contexto do
trabalho corporal, decorrente das exigências da técnica utilizada,
estabelece uma conexão entre a consciência de si e do outro. O uso do teatro de bonecos é utilizado, neste caso, como uma estratégia para trazer para a sala de aula o universo da consciência corporal, a valorização da alteridade a partir do saber da experiência e a introdução dos princípios técnicos da linguagem. Esta combinação nos permite estabelecer uma relação entre o conceito de alteridade e o teatro de bonecos.

Segundo Jorge Larrosa, não existe experiência sem o aparecimento de alguém ou de algo. "A experiência supõem, em primeiro lugar, um acontecimento ou, (...) o passar de algo que não sou eu. E 'algo que não sou eu' significa também algo que não depende de mim, (...)" (LARROSA, 2009, p. 5). Larrosa (2009) chama isso de "princípio de alteridade". Esse autor considera que isso que me passa tem que ser outra coisa que não eu, "não outro eu, ou outro como eu, mas outra coisa que eu. Quer dizer, algo outro, algo completamente outro, radicalmente outro". (Larrosa, 2009, p. 6).

Larrosa (2009) acredita para que haja experiência é preciso que o sujeito saia de si em direção a outro lugar. Um passo para outra coisa. Rumo a uma aventura ou a algo incerto. Algo que provoque risco e que represente algum perigo à estabilidade do sujeito que sabe e que pode. A experiência para Larrosa (2009) significa ir para fora e passar através de algo ou de alguém. Segundo o autor,

O saber da experiência não está, como o conhecimento científico, fora de nós, e, só tem sentido, no modo como configura uma personalidade, um caráter, uma sensibilidade ou, em definitivo, uma forma humana singular que é por sua vez uma ética (um modo de conduzir-se) e uma estética (um estilo) (Larrosa, 2009, p. 14). 
Nesse sentido, para Larrosa (2009) é fundamental pensarmos a experiência a partir da relação entre formação e transformação da subjetividade. Como o próprio autor diz: “(...) o sujeito de experiência seria algo como um território de passagem, algo como uma superfície de sensibilidade na qual aquilo que passa afeta de algum modo, produz alguns afetos, (...)" (Larrosa, 2009, p. 21).

Portanto, trata-se de pensarmos a experiência como algo que afeta nosso território de passagem e que, por isso, nos torna um sujeito exposto à experiência. Essa exposição, esse risco vivido durante o trajeto é fundamental para que haja a experiência. Desse modo, a experiência é atenção, escuta, abertura, disponibilidade, sensibilidade, vulnerabilidade e exposição (Larrosa, 2009, p. 22).

A contribuição de Larrosa para essa pesquisa com bonecos no contexto escolar, no que diz respeito ao conceito de alteridade em relação ao sentido da palavra experiência, foi fundamental, por considerar o saber da experiência atravessado pela paixão, pela incerteza ou pela singularidade, que combina perfeitamente com essa modalidade específica do universo do teatro de bonecos, em que o estudante tem de abrir mão de si para animar o boneco, isto é, emprestando o corpo como fonte de força motriz e imaginativa, além de realizar esses movimentos tendo que interagir com dois ou mais colegas de sala.

Acredito ser possível, a partir do manuseio dos bonecos, nos direcionarmos rumo à sensibilidade e à alteridade no contexto escolar. Isto porque estudantes de diferentes culturas se aproximam para realizar movimentos diferentes com o mesmo propósito de produzir uma sequência de movimentos que apresentem coerência na manipulação de um mesmo boneco.

Desta forma, isso me parece estar interligado com a necessidade de executarmos os princípios técnicos da linguagem para obtermos uma animação adequada e com a importância do dispositivo pedagógico, considerando-se a descrição e a análise das relações pedagógicas articuladas às estruturas de poder e controle social.

Por fim, a escolha do termo dispositivo pedagógico passa a ser mais um aspecto teórico que contribui para potencializar aquilo que a presente pesquisa tem como possibilidade de estudo, ou seja, o teatro de bonecos, que pode ser descrito e analisado pelas regras que compõem o dispositivo pedagógico de Basil Bernstein?

Outro autor que contribui para as reflexões sobre a relação entre alteridade e os bonecos no contexto escolar é o pesquisador Silvio Gallo (2008). As reflexões de Gallo (2009) auxiliam na reflexão sobre o conceito de alteridade no contexto de sala de aula e sobre a relação intrínseca entre pedagogia e bonecos, isto é, ajudam a pensar uma educação que modifica 
o entendimento do processo de ensino e aprendizagem pelo outro, não mais centrado a partir do indivíduo.

Gallo (2009) auxilia na reflexão sobre o conceito de alteridade na educação, considerando alguns estudos de Deleuze e Foucault, principalmente, a partir da noção deleuziana de dobra. A dobra Deleuziana, conhecida como fita ou banda de Moebius, é uma figura topológica que se tornou bastante representativa nas interrelações entre conceitos em Laban/Bartenieff, e é também uma figura central nas teorias do psicanalista Jacques Lacan.

Lacan definiu esta figura topológica como modelo de uma estética transcendente, no seminário de 15 de fevereiro de 1967. Esta subversão espacial, que a superfície da fita de Moebius opera, desliza sentidos e anula oposições entre verso e reverso. Isso instiga o olhar para outras regiões do entre e oferece a instabilidade de afirmações. Para Miranda (2008),

Se durante muitos anos parecia importante a busca de definições e certezas, com seu conseqüente discurso de verdades fundamentadas em oposições excludentes, os deslizamentos moebianos nos indicam caminhos de interpretações variadas, mas não excludentes, numa atitude que tende mais para ações de recriar e reinterpretar as circuntâncias do que de catalogá-las, ou marcá-las a ferro e fogo (MIRANDA, 2008, p. 59).

Gallo (2009) também se refere aos escritos do sociólogo Daniel Colson, que faz uma releitura das teses anarquistas do século XIX e XX como um dos autores da filosofia da diferença que pensa o outro como múltiplo de mim, e vê a dobra como elemento que se constitui nos diferentes outros dentro do eu. Esta noção de dobra contribui para que pensemos em uma educação a partir do outro.

$\mathrm{Na}$ filosofia da representação, em que o pensamento cartesiano entendia o "eu" como algo absoluto, quantificável e racional, não havia espaço para a subjetividade e para o entendimento deste "eu" pelo outro. Estes entendimentos empreendidos pelos autores da filosofia da diferença contribuíram para que na área educacional deslocássemos o processo de ensino e aprendizagem pautada no indivíduo para os múltiplos "eus" que há no coletivo.

Nesta pesquisa, o teatro de bonecos contribuiu para a materialização tanto da concepção de uma pedagogia da alteridade, quanto da concretização do processo de ensino e aprendizagem pelo outro, embora Deleuze defenda não ser possível controlar a aprendizagem, pois podemos, segundo ele, apenas inventar métodos para ensinar através de acontecimentos (GALLO, 2008).

Assim, o trabalho corporal apresenta-se como condição essencial para uma preparação adequada dos corpos que animam, mas também, dos 
corpos que se reconhecem mutuamente. Considerando isso, este trabalho corporal deve estar relacionado com o desejo de oferecer aos estudantes uma educação que considere o outro como uma das tantas dobras que constitui o "meu eu".

Deste modo, o conceito de alteridade deverá ser apresentado numa perspectiva horizontal de diálogo entre animador, boneco e espectador, como um aliado que contribui para uma educação de alteridade a partir da noção do outro.

Uma educação pelo outro é fundamental para estabelecer um processo de experiência de alteridade, que possibilite aos estudantes transpor suas fronteiras culturais ${ }^{1}$. Da mesma forma, aproximar suas fronteiras culturais possibilita a transposição destas fronteiras forjadas pela dominação, o que é fundamental para desafiar aquilo que nos define e nos constitui enquanto sujeitos.

Neste aspecto, transpor nossas fronteiras tornar-se, na contemporaneidade, uma exigência para que compreendamos o outro e a nós mesmos. Portanto, atribuir importância à experiência corporal exigida nesta linguagem cênica, que possibilita um diálogo entre o eu, o boneco e o outro, nos coloca em sintonia com o pensamento de Berta Vishnivetz, que diz que:

A consciência do si-mesmo ou self é também um meio de desenvolver a consciência do outro. Só na proporção em que estou sintonizado com meus próprios sentimentos, é que sou capaz de ser consciente dos sentimentos dos outros. Só na proporção em que estou consciente de minhas reações aos outros, é que sou capaz de sair de mim mesmo e amá-los sem causar-lhes dano algum. Quando me torno sensorialmente consciente de mim, também desenvolvo uma consciência refinada de meu irmão (Saddanah, 74, apud VISHNIVETZ, 1995, p. 46)

Nesta tentativa de adquirir a consciência de si mesmo, o estudante pode procurar se colocar no lugar do outro como animador. Isto também pode se dar com o próprio corpo do estudante. O teatro de bonecos é o meio e a ferramenta que poderá auxiliar o estudante a transitar entre o eu/ corpo e o outro/boneco. Além disto, esta modalidade de animação reúne particularidades técnicas e potencialidades estéticas que contribuem para a percepção do self e exige dos estudantes a produção de afetos, a aproximação de fronteiras culturais e a integração entre os corpos. Esta transferência de afetos, deslocamento de corpos e aproximação de fronteiras culturais possibilita a materialização de uma educação pautada na alteridade. 
A disciplina de Artes possui um caráter que supõe facilitar a integração das disciplinas do currículo através de uma mesma ação pedagógica. Por outro lado, na escola onde o projeto é proposto, existe, de maneira generalizada, um entendimento que separa o que é pedagógico daquilo que se passa no interior do estudante, o lado subjetivo. Percebe-se que se separa o psicofísico, artístico e criativo do lado racional. Isso repercute no desempenho dos estudantes e em suas relações com os conteúdos aprendidos e também com os resultados finais de aprovação e reprovação.

Em decorrência disso, pode-se elaborar uma série de reflexões e questionamentos sobre essas práticas. Parte-se da necessidade de se assumir um posicionamento enquanto educadores, denominados por Giroux como "intelectuais transformadores", para desenvolver uma proposta pedagógica como esta. Uma atitude assim é importante, tanto no que diz respeito a reivindicar espaços escolares que ofereçam o mínimo de condições para o desenvolvimento das aulas de teatro, quanto na exigência de espaços para o compartilhamento destas práticas pedagógicas inovadoras e de meios e instrumentos de divulgação destas reflexões e dos resultados, junto à comunidade escolar.

Este papel transformador, de que fala Giroux (1999), exige que pensemos a escola em sua dimensão expandida, isto é, indo para além das fronteiras da sala de aula e do pátio da escola. Assim, professores e estudantes podem, e devem, ser vetores das práticas artísticas junto à comunidade.

Considerando-se a necessidade de se trabalhar com uma perspectiva transformadora, numa concepção de pedagogia crítica, como defende Giroux (1999), é possível estabelecer outro paralelo entre o uso da linguagem do teatro de bonecos e a relação intrínseca entre os mecanismos de manipulação e controle social. Por isso, retornamos a Larrosa (2016), a partir do qual cabe refletir sobre o duplo sentido da palavra "manipulação". Segundo o autor,

[...], o periodismo é a fabricação da informação e a fabricação da opinião. E quando a informação e a opinião se sacralizam, quando ocupam todo o espaço do acontecer, então o sujeito individual não é outra coisa que o suporte informado da opinião individual, e o sujeito coletivo, esse que teria de fazer a história segundo os velhos marxistas, não é outra coisa que o suporte informado e manipulado pelos aparatos da informação e da opinião, um sujeito incapaz de experiência (LARROSA, 2016, p. 21).

2 O sociólogo da educação, Henry Giroux, associou dois conceitos, gerando um terceiro: o conceito de Foucault, do intelectual específico, assumindo lutas conectadas a questões e contextos particulares, com o conceito de Gramsci, do intelectual engajado, que relaciona o seu trabalho com interesses sociais mais amplos ao ponto de afetarem, profundamente, a maneira como as pessoas vivem, trabalham e sobrevivem. Giroux definiu que os produtores culturais, professores que assumem uma postura de engajados e transformadores numa concepção de pedagogia crítica, são denominados intelectuais transformadores (GIROUX, 1999, p. 99). 
Se somos fabricados pela informação e pela nossa própria opinião, como pensamos, quais as possíveis relações entre animar bonecos e manipular sujeitos? Podemos estabelecer uma relação direta entre os princípios técnicos fundamentais para uma "boa" animação e um poderoso e eficiente sistema de fabricação, manipulação e controle do sujeito?

Desta forma, é possível aproximar as reflexões de Larossa à função da informação como um instrumento de manipulação de nossa opinião, de modo que manipulados pelos aparatos da informação. Nesse sentido, a escolha do termo "dispositivo pedagógico", cunhado pelo sociólogo inglês Basil Bernstein, em 1986, segue nesta mesma direção.

Isto significa que a tentativa de interpretar os diferentes mecanismos e estruturas de poder e controle social, a partir da descrição e análise das relações pedagógicas escolares e em articulação com as estruturas de poder e controle mais amplo da sociedade, foi determinante na escola desse termo. Sendo assim, escolher o termo "dispositivo pedagógico" estava em consonância com aquilo que o sociólogo pesquisou durante quatro décadas de estudos. Em outras palavras, o "dispositivo pedagógico" desenvolvido por Bernstein é um modelo teórico que propõe desvelar a complexidade das práticas escolares e perceber suas constantes articulações com os contextos sociais.

Bernstein ocupou-se em investigar as dinâmicas internas das práticas pedagógicas e seu contexto social de inserção e articulação com as estruturas de poder e controle da sociedade. Desta maneira, no amadurecimento da sua pesquisa, avança no conhecimento dessa articulação, criando esse modelo teórico que possibilitou apresentar uma linguagem especial capaz de recuperar as macrorelações a partir das microinterações, apresentando, assim, como se resignam nas práticas curriculares as relações dominantes de poder e de controle enquanto formas de comunicação.

Dessa forma, a unidade de análise do modelo teórico desenvolvido por Bernstein foi a relação pedagógica na sua dimensão comunicativa. A definição do modelo teórico buscou criar uma linguagem que, ao gerar descrições específicas das práticas e discursos das relações pedagógicas, possibilitasse o estudo dos processos concretos de transmissão e aquisição de conhecimentos, valores e formas de consciência (LEITE, 2004, p. 22)

Em sua última publicação, Bernstein investiga o que denominou de processo de pedagogização do conhecimento. Seu objetivo foi criar uma linguagem conceitual capaz de descrever os caminhos de construção do discurso e da prática das relações pedagógicas, de forma que prioriza os contextos escolares e considera fundamental a forma como se constitui a configuração desses saberes nesses ambientes escolares. Isso demonstra a importância que Bernstein concede aos processos comunicativos na educação e aos conteúdos veiculados nessas interações. O autor define o disposi- 
tivo pedagógico como quem regula a comunicação e a partir de um sistema de regras que se referem à prática e ao discurso pedagógico.

Embora, utilize o termo "dispositivo pedagógico", desenvolvido por Basil Bernstein, não tenho o objetivo, nessa pesquisa, de me aprofundar na descrição e na análise das relações pedagógicas estabelecidas a partir da experiência vivenciada no universo do teatro de bonecos, apesar de haver essa possibilidade.

De qualquer forma, o que me interessa na utilização do termo - e, respectivamente, na definição do modelo teórico elaborado e desenvolvido por Bernstein em relação à pesquisa com bonecos - é a aproximação entre as estruturas de poder, os aparatos de manipulação da informação e da opinião que impedem o saber da experiência, segundo Larrosa, e o controle simbólico, denunciado pelo "dispositivo pedagógico". Este regula a comunicação a partir de um sistema de regras, que se referem à prática e ao discurso pedagógico, elaboradas por Basil Bernstein, bem como às necessidades que a linguagem do teatro de bonecos exige de seus animadores, na busca por um processo de conscientização corporal que lhes permita integrar movimentos próprios com movimentos dos colegas, em função da manipulação de um mesmo boneco.

O entendimento dessas estruturas de poder e controle social, bem como dos diferentes aparatos de manipulação da informação e da opinião, está relacionado aos processos de conscientização sobre como utilizar nosso corpo junto ao corpo do outro, em busca da coerência do movimento com o boneco. Isto me parece, ainda, estar em sincronia e integração com a busca de diferentes conceitos que se complementem e elaborem soluções compatíveis com os paradigmas na educação atual.

\section{CONSCIENTIZAÇÃO E PREPARAÇÃO CORPORAL NO TEATRO DE BONECOS}

$\mathrm{P}$ ara refletir sobre a importância da conscientização corporal e sobre o teatro de bonecos, é oportuno fazer referência às dissertações de Marcelle Teixeira Coelho (2010) e José Oliveira Parentes (2007). Estes pesquisadores analisam em seus estudos diferentes técnicas da educação somática para auxiliar e complementar suas investigações na preparação corporal destes corpos que animam.

A partir destas leituras, pode-se perceber a importância de se realizar um processo baseado na exploração da percepção, sensibilização e conscientização corporal para se obter uma animação convincente e consistente. 
Assim, pode-se estabelecer a relação entre a experiência disparada, a partir do processo de conscientização corporal, associado ao teatro de bonecos.

A experiência, a consciência corporal e os princípios técnicos da linguagem são fundamentais e compõem uma mesma atmosfera, no que se refere aos processos de criação da cena, ou seja, existe entre eles uma conexão imanente, na qual cada um afeta e potencializa as emoções e os sentimentos dos envolvidos. Assim, o estudante, a partir da percepção de si, pode conduzir-se a conhecer o outro, transpondo os limites daquilo que define como sendo eu, em direção àquilo que me afeta pelo outro.

Considerando a importância de buscarmos uma educação pela alteridade e o acontecimento como prova desta experiência com o outro, a partir da consciência de nós mesmos, retomamos Larrosa (2016):

A experiência, a possibilidade de que algo nos aconteça ou nos toque, requer um gesto de interrupção, um gesto que é quase impossível nos tempos que correm: requer parar para pensar, parar para olhar, parar para escutar, pensar mais devagar, olhar mais devagar, e escutar mais devagar; parar para sentir, sentir mais devagar, demorar-se nos detalhes (LARROSA, 2016, p. 25).

Isso nos conduz a experimentar procedimentos que impliquem em diminuir os ritmos, numa sociedade de consumo e globalizada, para percebermos os detalhes e, principalmente, aquilo que nos toca e nos afeta, a partir da percepção do outro. Nesse sentido, pode-se destacar o uso do teatro de bonecos como uma possibilidade de ressignificar o tempo, os ritmos das coisas e do olhar.

O trabalho detalhado com estes elementos é fundamental para uma animação adequada, além de potencializar esta relação intrínseca entre a modalidade técnica (direta-visível), a fabricação e a manipulação do sujeito, bem como a importância da experiência criativa como disparadora de afeto, emoções e sentimentos.

Nesta experiência, à qual se refere este texto, a metodologia de trabalho foi estruturada a partir do processo de conscientização corporal, que utilizou alguns exercícios de eutonia, como por exemplo: contato consciente, contato consigo e com outro e contato com objetos (VISHNIVETZ, 1995), além de respiração diafragmática desenvolvida na yoga, como "comprimento ao sol", por exemplo, e exercícios destinados a bonecos articulados com animação direta-visível.

Aprender a olhar, se mover e desacelerar o ritmo é algo fundamental no teatro de bonecos. Para se conseguir movimentos comedidos é preciso, antes de tudo, aprender e incorporar concretamente no corpo esta conscientização (BELTRAME, 2003).

Ana Maria Amaral afirma que a primeira etapa do trabalho do ator é aprender a sair de si. $\mathrm{O}$ ator/bonequeiro deve perceber suas tensões, estar 
aberto e disponível, comunicando-se com o seu próprio corpo, estar em prontidão e alerta com seu corpo. Por isso, acredita-se que "ao manipular um objeto estranho, mas a ele ligado (como máscaras) ou distanciado (como bonecos e objetos) o ator desloca o foco de si para algo fora dele mesmo, e isso o ajuda a se perceber melhor" (AMARAL, 2002, p. 21).

Práticas deste tipo ajudam e contribuem para que nos coloquemos no lugar do outro e nos desloquemos para fora de nós mesmos. De acordo com Amaral, este distanciamento que surge entre a distância do boneco e o animador contribui na tomada de consciência de si.

O processo de conscientização corporal e as reflexões que este tipo de trabalho geram durante a preparação corporal são fundamentais para realizarmos um trabalho significativo, tanto como resultado artístico e expressivo, quanto educativo, reflexivo e de autoconhecimento.

É válido lembrar que estamos falando de estudantes de uma Escola Pública Estadual de Ensino Médio, e que, ao mesmo tempo, é perfeitamente possível fazer um paralelo entre o universo do teatro de bonecos profissional e acadêmico e a realidade de estudantes da escola. Esta modalidade de teatro de bonecos possibilita que o estudante se distancie de seu próprio corpo. Sendo assim, não é preciso ser um artista profissional para experimentar práticas radicais, ainda que seja necessário considerar as especificidades de cada um dos contextos.

\section{Teoria e Prática no Espaço Escolar}

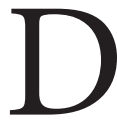

iante de uma sociedade cada vez mais influenciada e dependente das tecnologias midiáticas, outro aspecto importante na escolha desta linguagem cênica é a necessidade de fomentar, no ambiente escolar, uma atmosfera prática de vivência artística.

Esta prática deve ser encarada como necessidade de preparação corporal destes corpos que animam. Ao mesmo tempo, isto exige um processo de construção das animações que comprometa os estudantes fisicamente, uma vez que é necessário o uso do corpo, tanto como instrumento expressivo, quanto como de suporte estético. Assim a fusão teoria e prática serão interdependentes e imanentes ${ }^{3}$.

Neste aspecto, o teatro de bonecos é fundamentalmente uma ideia, além de movimentos materializados no espaço, sendo que uma coisa não

3 Segundo Paulo Balardim, a arte da animação teatral é basicamente adquirida a partir da experiência, mas, para isso, é preciso abolir, antes de tudo, o paradigma que separa teoria e prática (BALARDIM, 2004, p. 80). 
existe sem a outra. O conhecimento sem ação pedagógica restringe o potencial das informações e dos conteúdos, e uma educação pela alteridade reconhece na diferença o potencial criativo dos estudantes, a partir de práticas pedagógicas inovadoras que auxiliam a integração dos conhecimentos científicos, psicofísicos e artísticos.

O conhecimento dos aspectos teóricos sem uma materialização, sem um processo de experimentação e não vivenciado pelos estudantes torna qualquer processo educativo frágil e limitado. Assuntos, conteúdos e informações tendem a ser esquecidos rapidamente, sem fazer diferença na vida do estudante, portanto é fundamental que consideremos teoria e prática em união.

Além disso, considerar a razão e os processos intelectuais como os únicos responsáveis pelo crescimento pessoal contraria os aspectos mais significativos da eutonia, cujo principal objetivo é despertar e desenvolver a consciência da unidade psicofísica do indivíduo. Em outras palavras, ao trabalhar com a capacidade humana de mover-se e deslocar-se no espaço, e com isto desenvolver a consciência dessa capacidade, permitimos uma melhora na qualidade do movimento que influencia a pessoa de maneira geral ${ }^{4}$.

O movimento anima o corpo, produz processos de afetação e é a síntese da vida. As informações e conhecimentos adquiridos só poderão fazer sentido se pensarmos estes diferentes conhecimentos de forma que conduzam e concretizem processos de experimentações, que direcionam os estudantes rumo a uma trajetória singular, compartilhada, emancipadora e altruísta. Nisto se insere o teatro de bonecos, que é a ferramenta de minha pesquisa, pois, contribui para reunir numa mesma trajetória de trabalho pedagógico aspectos técnicos, metodológicos, artísticos, interdisciplinares e de autoconhecimento.

\section{CONSIDERAÇÕES FINAIS}

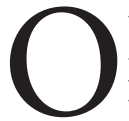

teatro de bonecos pode ser disparado a partir do trabalho corporal, enquanto uma experiência que afeta e transforma os participantes. Esta relação entre os princípios técnicos da modalidade de animação direta-visível e a preparação corporal faz do teatro de bonecos um dispositivo pedagógico de extrema potência. Neste sentido, a proposta pedagógica desenvolvida nessa escola poderia, de alguma forma, ser descrita e analisada a partir das relações pedagógicas estabe- 
lecidas durante o processo de criação e execução.

De qualquer forma, essa modalidade teatral nos afeta e nos transforma também pelos aspectos lúdico e prazeroso de seu próprio fazer. O universo do teatro de bonecos é uma linguagem cênica que transita em qualquer faixa etária. Isto significa dizer que o teatro de bonecos, enquanto modalidade específica do teatro de animação, vai de zero a oitenta anos, ou seja, não existe contraindicação.

Nesse sentido, segundo Amaral (1996) "o teatro de bonecos tem uma relação direta com o pensamento animista infantil, tem todas as condições para satisfazer os anseios de transformações que a criança tem de tornar real os seus sonhos de poder" (AMARAL, 1996, p. 171), o que não o torna restrito a outras faixas etárias.

O teatro de bonecos oferece uma atmosfera de divertimento, relativo ao jogo e ao brinquedo, e de uma convivência prazerosa, mas não menos conflitante em seu fazer e apreciar, tanto para o participante atuante, quanto para o participante espectador. Este pensamento pode ser relacionado às ideias de Berta Vishnivetz, que entende que a consciência de si ajuda a desenvolver a consciência do outro.

A perspectiva que orienta meu olhar neste trabalho reafirma que quando um sujeito se sintoniza com seus sentimentos, pode ter consciência dos sentimentos dos outros. Isso se relaciona com o ponto de vista de Ana Maria Amaral, que explica que a primeira etapa do trabalho do ator é aprender a sair de si. Deste modo, pode-se atingir uma prática educativa que considere a experiência a partir de si e pelo outro como sendo fundamental na formação e capacitação dos estudantes, uma educação que, segundo Larossa, possibilite que algo nos aconteça, nos transforme.

Finalmente, cabe dizer que a busca desta integração, na experiência que venho realizando na escola, necessita de mais referenciais bibliográficos para sustentar e ampliar o uso desta linguagem no contexto escolar, tarefa em desenvolvimento.

Apesar da evidente aproximação entre o lado lúdico e pedagógico do universo do teatro de bonecos e a escola, ainda existe pouco material bibliográfico que investigue a utilização do teatro de bonecos no contexto escolar, já que este é um campo de pesquisa que está em crescimento, mas ainda é incipiente. Por isso, é importante se perguntar como o teatro de bonecos pode ser mais que um recurso didático, e este texto é um convite ao debate sobre esta proposta pedagógica. 


\section{REFERÊNCIAS}

AMARAL, Ana Maria. Teatro de Formas Animadas: Máscaras, Bonecos, Objetos. $3^{\circ}$ ed. São Paulo: Editora da Universidade de São Paulo, 1996.

, O Ator e Seus Duplos: máscaras, bonecos, objetos. São Paulo: Editora SENAC São Paulo, 2002.

BALARDIM, Paulo. Relações de vida e morte no teatro de animação. Porto Alegre: Edição do Autor, 2004.

BELTRAME, Valmor. (org.) Teatro de Bonecos: distintos olhares sobre teoria e prática. In: Princípios técnicos do trabalho do ator-animador. Valmor Níni Beltrame. Florianópolis: UDESC, 2008, p. 25-40.

BELTRAME, Valmor. O Trabalho do Ator-Bonequeiro. In: Revista NUPEART, Florianopolis: UDESC, SC, v.2, n.2, p. 33-52, set. 2003.

BERNSTEIN, B. A estrutura do discurso pedagógico: classe, códigos e controle. Vozes: Petrópolis, 1996.

COELHO, Marcelle Teixeira. O corpo no teatro de animação: contribuições da educação somática na formação do ator. 2010. Dissertação (Mestrado em Teatro) Centro de Artes, Universidade do Estado de Santa Catarina, Florianópolis.

GALLO, Sílvio. Eu, o outro e tantas outros: educação, alteridade e filosofia da diferença. Anais do II Congresso Internacional Cotidiano: Diálogos sobre Diálogos. Universidade Federal Fluminense, Rio de Janeiro. 2008.

GIROUX, Henry A. Cruzando as fronteiras do discurso educacional: novas politicas em educação. Porto Alegre: Artes Médicas Sul, 1999.

LARROSA, Jorge. Tremores: escritos sobre experiência. Belo Horizonte: Autêntica, 2016.

LARROSA, Jorge e Skliar, Carlos. Experiencia y alteridade em educación. Revista Reflexão e Ação, Santa Cruz do Sul. V.19, nº 22, p.04-27, jul./ dez.2011. 
LEITE, Miriam Soares. Contribuições de Basil Bernstein e Yves Chevallard para a discussão do conhecimento escolar. 2004. Dissertação (Mestrado em Educação do Departamento de Educação do Centro de Teologia e Ciências Humanas da PUC, Rio de Janeiro.

MAINARDES, Jefferson e STREMEL, Silvana. A teoria de Basil Bernstein e algumas de suas contribuições para as pesquisas sobre política educacionais e curriculares. Revista Teias. V.11, n 22, p. 31-54, maio/agosto, 2010.

MIRANDA, Regina. Corpo-espaço: aspectos de uma geofilosofia do corpo e movimento. Rio de Janeiro: 7 Letras, 2008.

PARENTE, José Oliveira. Preparação corporal do ator para o teatro de animação - uma experiência. 2007. Dissertação (Mestrado em Teatro). Universidade de São Paulo, São Paulo.

VISHNIVESTZ, Berta. Eutonia: educação do corpo para o ser. São Paulo: Summus, 1995.

BELTRAME, Valmor. (org.) Teatro de Bonecos: distintos olhares sobre teoria e prática. In: SOUZA, Alex. Reflexões sobre a animação à vista do público. Florianópolis: UDESC, 2008, p. 80-90. 